medRxiv preprint doi: https://doi.org/10.1101/2022.02.03.22270310; this version posted February 4, 2022. The copyright holder for this preprint (which was not certified by peer review) is the author/funder, who has granted medRxiv a license to display the preprint in perpetuity.

It is made available under a CC-BY 4.0 International license .

\title{
Placental microRNAs associate with early childhood growth characteristics
}

Elizabeth M. Kennedy ${ }^{1}$, Karen Hermetz ${ }^{1}$, Amber Burt ${ }^{1}$, Dong Pei ${ }^{2}$, Devin C Koestler ${ }^{2}$, Ke Hao ${ }^{3}$, Jia Chen ${ }^{4}$, Diane Gilbert-Diamond ${ }^{5}$, Usha Ramakrishnan ${ }^{6}$, Margaret R. Karagas ${ }^{7}$, Carmen J Marsit $^{1 *}$

${ }^{1}$ Gangarosa Department of Environmental Health, Rollins School of Public Health, Emory University, Atlanta, Georgia

${ }^{2}$ Department of Biostatistics \& Data Science, University of Kansas Medical Center, Kansas City, Kansas

${ }^{3}$ Department of Genetics and Genome Sciences, Icahn School of Medicine at Mount Sinai, New York, New York

${ }^{4}$ Department of Environmental Medicine and Public Health, Icahn School of Medicine at Mount Sinai, New York, New York

${ }^{5}$ Department of Epidemiology, Geisel School of Medicine, Dartmouth College, Lebanon, New Hampshire

${ }^{6}$ Hubert Department of Global Health, Rollins School of Public Health, Emory University, Atlanta, Georgia

${ }^{7}$ Children's Environmental Health and Disease Prevention Research Center at Dartmouth, Dartmouth College, Lebanon, New Hampshire

\section{*Corresponding Author:}

Email address: carmen.j.marsit@emory.edu

Permanent Address:

1518 Clifton Road

Claudia Nance Rollins Room 2021

\begin{abstract}
Poor placental function is a common cause of intrauterine growth restriction, which in turn is associated with increased risks of perinatal morbidity, mortality and long-term adverse health outcomes. Our prior work suggests that birthweight and childhood obesity-associated genetic variants functionally impact placental function and that placental microRNA are associated with birthweight. To address the influence of the placenta beyond birth, we assessed the relationship between placental microRNAs and early childhood growth. Using the SITAR package, we generated two parameters that describe individual weight trajectories of children (0-5 years) in the New Hampshire Birth Cohort Study (NHBCS). Using negative binomial generalized linear models, we identified placental microRNAs that associate with growth parameters $(\mathrm{FDR}<0.05)$, while accounting for sex, gestational age at birth, and maternal parity. Genes targeted by the six growth trajectory-associated microRNAs are enriched $(\mathrm{FDR}<0.02)$ in growth factor signaling (TGF/beta: miR-1290; EGF/R: miR-155, Let-7c; FGF/R: miR-155; IGF/R: Let-7c, miR-155, miR-1290), cyclic AMP signaling (miR-1246), calmodulin signaling (miR-216a, miR-1246), and NOTCH signaling (miR-629). These pathways function in placental proliferation, differentiation and function. Our results support the hypothesis that fetal environment, specifically placental cellular dynamics and function guided by microRNA expression, can have impacts beyond birth, into early childhood.
\end{abstract}




\section{INTRODUCTION}

2 The Developmental Origins of Health and Disease (DOHaD) posits that in utero exposures can

3 induce permanent maladaptive changes that "program" the fetus to have increased risk of later-

4 life diseases ${ }^{22}$. The placenta is the master regulator of the intrauterine environment and an ideal

5 tissue in which to test the $\mathrm{DOHaD}$ paradigm. This ephemeral organ facilitates the exchange of

6 gases, nutrients and waste for the developing embryo ${ }^{23,24}$, in addition to aiding nutrient

7 metabolism, and acting as an endocrine organ critical for early development. Thus, its functions

8 are responsible for proper development and programming of the offspring.

MicroRNAs are 21-25 base pair non-coding RNAs that regulate gene expression post-

transcriptionally via sequence complementarity to the 3' untranslated region of mRNA

11 transcripts. microRNA-mediated gene regulation is achieved through target mRNA translational

12 inhibition or degradation ${ }^{25}$. MicroRNAs are proposed to regulate more than $50 \%$ of human genes

$13 \quad 25-28$, emphasizing their dynamic utility as post-transcriptional regulators of gene expression.

14 Placental microRNAs shape placental development and function by targeting genes that regulate

15 trophoblast proliferation and differentiation, apoptosis, invasion, cellular metabolism, as well as

16 vasculo- and angio-genesis ${ }^{28}$. In a study of placental microRNA sequencing data from more than

17500 mother-infant pairs, in two independent cohorts, we have previously identified a group of

18 placental microRNAs that are associated with birthweight. The most robust birthweight

19 differentially expression microRNA, miR-532, was associated with the differential expression of

20 placental adipokines, leptin and adiponectin receptor ${ }^{1}$.

21 The placental transcriptome may have lasting metabolic impact beyond birth. Using

22 parallel genomic and transcriptomic data from the Rhode Island Child Health Study (RICHS),

23 Peng et al. reports that DNA variants that predict placental gene expression level (eSNPs) for a 
24 given gene are over-represented among loci that associate with childhood obesity and BMI ${ }^{29}$.

25 Compared to eQTLs for seven adult tissues, placental eQTLs were most strongly enriched

26 among results from GWASs of birthweight, childhood obesity, and childhood BMI. These

27 results demonstrate that the placental transcriptional landscape can have a lasting impact on early

28 childhood growth and metabolism ${ }^{29}$.

In this study, we pose the question: Do microRNAs that regulate the placental mRNAs

31 weight from birth to five years of age in the New Hampshire Birth Cohort Study (NHBCS).

32 Using parameters derived from individual growth curves, we relate placental microRNA

33 expression, from small-RNA sequencing, with early childhood growth. We use in silico methods

34 to predict mRNA targets of interesting microRNAs and pathway analysis to add biological

35 context to our findings.

\section{MATERIALS AND METHODS}

\section{Cohort}

The New Hampshire Birth Cohort Study. NHBCS was initiated in 2009 and is an ongoing

39 study comprised of a cohort of mother-infant pairs. Pregnant women between 18 and 45 years of

40 age were recruited from the study's participating prenatal care clinics in New Hampshire, USA.

41 Women were included in the cohort if their primary source of drinking water was from an

42 unregulated residential well, they had resided in the same household since their last menstrual

43 period and had no plans to move before delivery. All participants provided written informed

44 consent in accordance with the requirements of the Committee for the Protection of Human

45 Subjects, the Institutional Review Board (IRB) of Dartmouth College. In this study, NHBCS

46 participants were singleton pregnancies recruited between February 2012 and September 2013. 
medRxiv preprint doi: https://doi.org/10.1101/2022.02.03.22270310; this version posted February 4, 2022. The copyright holder for this preprint (which was not certified by peer review) is the author/funder, who has granted medRxiv a license to display the preprint in perpetuity.

It is made available under a CC-BY 4.0 International license.

\section{Data collection}

48 Anthropomorphic measures. NHBCS has parallel demographic and anthropomorphic measures

49 for mothers and newborns, as well as placental microRNA transcript abundance. Up to 14 weight

50 measurements between birth and five years of age were abstracted from pediatric medical

51 records (Ages: birth, 2 weeks, 1 month, 2 months, 4 months, 6 months, 9 months, 12 months, 15

52 months, 18 months, 2 years, 3 year, 4 years and 5 years; Fig. 1). Study participants were

53 excluded from the analysis if they had less than three separate weight observations, but were not

54 excluded for intermediate missing observations (Fig. 1).

55 Additional study covariates. Gestational age and fetal sex were abstracted from newborn

56 medical records. $z$-Scores were calculated for gestational age. Self-reported maternal parity was

57 collected by questionnaire.

58 Tissue collection. Fetal placental samples were collected at delivery; sections were obtained two

59 centimeters $(\mathrm{cm})$ from the umbilical cord and free of maternal decidua. Collected tissue was

60 immediately placed in RNA later solution (Life Technologies, Grand Island, NY, USA) and

61 stored at $4{ }^{\circ} \mathrm{C}$ for at least 72 hours and stored at $-80{ }^{\circ} \mathrm{C}$.

62 microRNA isolation and sequencing. Total RNA was extracted from placenta using the Qiagen

63 miRNeasy Mini Kit and a TissueLyser LT (Qiagen, Frederick, MD, USA) following

64 manufacturer's protocol. Briefly, $25-35 \mathrm{mg}$ of placental tissue was placed in a $2 \mathrm{ml}$ round bottom

65 tube with $700 \mathrm{ul}$ of Qiazol Lysing Reagent and one $5 \mathrm{~mm}$ stainless steel bead. The tissue was

66 homogenized on the TissueLyser LT for 2 minutes at $40 \mathrm{~Hz}$. The resulting homogenate was

67 processed with the Qiagen miRNeasy Mini Kit and eluted in $30 \mu 1$ RNase-free water. The RNA

68 was quantitated on a NanoDrop 2000 (Thermo Fisher, Waltham, MA, USA) and quality checked

69 on Agilent Bioanalyzer using the Agilent RNA 6000 Nano kit (Agilent, Santa Clara, CA, USA). 
medRxiv preprint doi: https://doi.org/10.1101/2022.02.03.22270310; this version posted February 4, 2022. The copyright holder for this preprint (which was not certified by peer review) is the author/funder, who has granted medRxiv a license to display the preprint in perpetuity.

It is made available under a CC-BY 4.0 International license.

70 Single end, 1 x 75 bp next generation sequencing of placental microRNA was performed by

71 Qiagen Genomic Services (Frederick, Maryland).

72 smallRNA-Seq Processing and Quality Control. Raw FASTQ reads obtained from a total of

73552 (RICHS 230, NHBCS 322) samples were subject to adaptor trimming with cutadapt v1.16

$74{ }^{30}$. The $3^{\prime}$ adaptor sequence (AACTGTAGGCACCATCAAT) was trimmed based on vendor's

75 recommendation (Qiagen). After adaptor trimming, fast $Q C \mathrm{v} 0.11 .5$ was used to process the

76 trimmed reads and QC results were aggregated using MultiQC v1.5 for visualization ${ }^{31}$. One

77 sample failed QC and was removed. Then we used trimmed reads and miRDeep2 to quantify

78 microRNA ${ }^{32}$. In short, miRDeep2 was used to first perform alignment using bowtie1 with human

79 genome hg38 ${ }^{33}$. The 'Quantifier' module in miRDeep2 was used to obtain raw counts of

80 microRNAs with miRBase version $22^{34}$.

81 Sample filtering and transcript filtering. Raw counts were imported into DESeq2 for

82 normalization and differential expression analysis. microRNAs with less than one count per

83 million in more than 10 percent of samples were removed. Of the 2,656 microRNA transcripts

84 that mapped, 777 remained after filtering, respectively.

85 Normalization. Filtered microRNA raw counts were imported to DESeq2 for normalization and

86 differential expression analysis. For all data sets, parametric estimates of dispersion were

87 calculated, and the median ratio method was used to estimate size factors for normalization for

88 modeling with DESeq ${ }^{35}$. Normalized counts were exported from DESeq2 for surrogate variable

89 analysis. RICHS RNAseq count data are available via dataverse

90 (https://doi.org/10.15139/S3/FUC5EW) and the methods for collection and processing are

91 available elsewhere ${ }^{1}$. 
medRxiv preprint doi: https://doi.org/10.1101/2022.02.03.22270310; this version posted February 4, 2022. The copyright holder for this preprint (which was not certified by peer review) is the author/funder, who has granted medRxiv a license to display the preprint in perpetuity.

It is made available under a CC-BY 4.0 International license.

93 Statistical analyses

94 Modeling childhood growth trajectory. The R package SITAR was used to model growth

95 trajectory for all study participants with at least three weight observations $(n=238)^{36}$. Individual

96 children's growth curves were visually assessed for outlier measures. Three observations were

97 removed (Fig. S1). The children's weights were natural log transformed to meet the normality

98 assumption of the SITAR method. Briefly, SITAR is a shape invariant model, with individual

99 random effects for each child, that estimates an average growth curve across samples. A set of

100 three parameters are generated for each individual that, through translation (vertical/horizontal

101 shift) and rotation (counter/clockwise), transform the average growth curve to match each

102 individual's growth. The parameters, random effects, have mean zero and standard deviations

103 estimated from the data. These parameters - size, intensity and tempo, are interpreted as

104 percentiles relative to the average because the weights were natural log transformed. The size

105 parameter represents average size for any child relative to the average child and is graphically

106 represented as a vertical shift of the weight curve (Fig. 2). Tempo, the age at peak weight

107 intensity, was not estimated for this analysis, since no measures were estimated around the peak

108 of infant growth (6 weeks); intensity is expressed as a percentage deviation from mean

109 intensity with higher values representing faster growth than average. Graphically, intensity

110 represents a rotation of the weight curve (Fig. 2). We modeled the transformed weights using 10

111 degrees of freedom, and adjusted for child sex in the models that generated the size and intensity

112 parameters.

113 Surrogate variable analysis. To adjust for batch effects, cell-type heterogeneity and other

114 unknown sources of technical variation, we estimated a surrogate variable from the normalized

115 transcript reads via the svaseq function in the sva package that incorporates the Combat 
medRxiv preprint doi: https://doi.org/10.1101/2022.02.03.22270310; this version posted February 4, 2022. The copyright holder for this preprint (which was not certified by peer review) is the author/funder, who has granted medRxiv a license to display the preprint in perpetuity.

It is made available under a CC-BY 4.0 International license .

116 algorithm ${ }^{37,38}$. In the svaseq function, the iteratively re-weighted least squares algorithm was

117 used to estimate a surrogate variable based on empirically-derived control transcripts. The full

118 model (mod argument) used for svaseq differed by application. The null model (mod0 argument)

119 used all covariates except the outcomes variables - intensity and size.

120 Differential expression analyses. microRNA transcript counts were modeled using a negative

121 binomial generalized linear model with significance testing for differentially expressed

122 transcripts via Wald tests in DESeq2 ${ }^{39}$. The microRNA transcripts were regressed on either the

123 size or intensity parameters from SITAR. The intensity analysis included covariates for parity

124 and gestational age (z-score). Three samples were missing information for parity and were

125 removed from the intensity analysis $(\mathrm{n}=235)$. The size analysis included covariates for

126 primigravida and maternal educational (beyond high school). Five samples were missing

127 information for the maternal education variable and were removed from the size analysis $(\mathrm{n}=$

128 230). One surrogate variable was also included as a covariate in both regression models

129 (discussed in previous section). We considered microRNAs with a false discovery rate less than

$1305 \%$ to be differentially expressed with either size or growth intensity.

131 Sensitivity analysis. To assess potential confounding of DEmiR effects by pre-eclampsia,

132 maternal pre-pregnancy BMI, gestational weight gain or birthweight, potential confounders were

133 individually added to the DEA model in DESeq2. Effect estimates and standard errors were

134 collected for intensity and size DEmiRs for comparison with original model statistics.

135 Target mRNA prediction. Potential mRNA targets of significant microRNAs were identified

136 from mirDIP, an online database of human microRNA-target predictions ${ }^{40}$. mirDIP integrates

137 microRNA target prediction across 30 different resources, providing nearly 152 million human

138 microRNA-target predictions. Using the individual source ranking and confidence measures, 
medRxiv preprint doi: https://doi.org/10.1101/2022.02.03.22270310; this version posted February 4, 2022. The copyright holder for this preprint (which was not certified by peer review) is the author/funder, who has granted medRxiv a license to display the preprint in perpetuity.

It is made available under a CC-BY 4.0 International license .

139 mirDIP assigns a unified rank and confidence score using the quadratic function. For this

140 analysis, the predictions with the top $1 \%$ confidence scores (very high confidence) were returned

141 for each microRNA ${ }^{40}$. The resulting microRNA-target mRNA pairs were carried forward in the

142 analysis.

143 Putative target filtering. Predicted microRNA-target mRNA pairs were excluded if the

144 mRNAs were not expressed in placenta in the RICHS whole transcriptome data.

145 Pathway analysis. Pathway over-representation analysis was conducted in consensuspathDB ${ }^{41}$,

146 which aggregates data from 12 separate pathway analysis databases. For each pathway gene set,

147 consensus path DB calculates a p-value according to the hypergeometric test for the genes in

148 both the putative target genes and the pathway gene set. All mRNAs not filtered for low reads in

149 the RICHS whole transcriptome dataset were included as the background, or null distribution, for

150 the test.

$151 \quad$ RESULTS

This study analyzed data from 238 mother-infant pairs from the New Hampshire Birth

153 Cohort (NHBCS). Parallel placental microRNA transcript abundance was available for this

154 cohort, as well as up to 14 weight measures between birth and 5 years, collected from well-child-

155 checks. Study participants were excluded from the analysis if they had less than three separate

156 weight observations, but were not excluded for intermediate missing observations (Fig. 1).

157 Observations as a fraction of participants in the study at each measurement remained high

158 throughout the study, despite attenuated participation with time, especially after one year (Fig.

159 1). $48 \%$ of participants had at least 12 of the 14 potential observations and only $2 \%$ had less than

1605 observations (median observations across participants is 11, ranged 3-14). 
medRxiv preprint doi: https://doi.org/10.1101/2022.02.03.22270310; this version posted February 4, 2022. The copyright holder for this preprint (which was not certified by peer review) is the author/funder, who has granted medRxiv a license to display the preprint in perpetuity.

It is made available under a CC-BY 4.0 International license .

161 Growth Trajectory modeling. We modeled childhood weight growth trajectory using

162 SuperImposition by Translation And Rotation (SITAR) ${ }^{36}$. SITAR provided two parameters to

163 describe each child's growth. The size parameter is given as a percent, relative to the fitted

164 weight curve for all participants, for the average size of each individual child. Higher size is

165 graphically represented as an upward vertical shift in a child's weight growth curve. The size

166 parameter in this analysis ranged between $-37 \%$ and $31 \%$ (Fig. 2, red and blue lines). The

167 intensity parameter is expressed as a percentage deviation from the mean intensity for all

168 participants, with higher values representing faster growth than average. Higher growth intensity

169 is graphically represented as a counterclockwise rotation in a child's weight growth curve. The

170 intensity parameter for this analysis ranged between $-9 \%$ and $12 \%$ (Fig. 1, purple and cyan lines).

171 The demographics of the participants for this study are shown in Table 1. Due to

172 missingness in variables included in the models for the intensity and size differential gene

173 expression analysis, three children were excluded in the intensity analysis $(\mathrm{n}=235)$ and eight

174 children were excluded in the size analysis $(\mathrm{n}=230)$. The exclusion of children for the

175 downstream analysis did not change the demographic distributions for each analysis (data not

176 shown).

177 Differential microRNA expression analysis. To analyze the associations between growth

178 trajectory parameters and placental microRNA expression, we performed differential expression

179 analysis. For each growth trajectory parameter and microRNA transcript individually, transcript

180 abundances were regressed on corresponding growth trajectory parameter using DESeq2 ${ }^{39}$.

181 Covariates were included in the model if they were associated with the variable of interest

182 (intensity or size) in univariate regression analyses (Table 2). For the intensity analysis, models

183 also included maternal parity, gestational age (z-scores) and one surrogate variable (to account 
184 for batch effects, cell type heterogeneity, and other sources of unknown variability). For the size 185 analysis, primigravida, maternal educational attainment and one surrogate variable were included 186 in the models. Of the 777 microRNA transcripts that passed quality control filtering for the 187 analyses, five and one had an FDR $<0.05$ for the intensity and size analyses, respectively (p188 value $<1.4 \times 10^{-4}$, Fig.s 3, S2). For the intensity and size analyses, respectively, two and one of 189 those microRNAs had p-values less than the Bonferroni family-wise error rate threshold (p-value $190<6.4 \times 10^{-5}$, Fig.s 3, S2).

191 MicroRNAs that associate with intensity are hsa-miR-155-5p (estimate $=0.12$; standard 192 error: 0.02; FDR $\left.=8.7 \times 10^{-5}\right)$, hsa-miR-1290 (estimate $=0.11 ;$ standard error: $0.03 ;$ FDR $=$

$\left.1937.7 \times 10^{-3}\right)$, hsa-let-7c-5p (estimate $=-0.03$; standard error: 8x10 $0^{-3} ;$ FDR $\left.=0.02\right)$, hsa-miR-1246

194 (estimate $=0.08$; standard error: $0.02 ; \mathrm{FDR}=0.02)$, and hsa-miR-629-3p (estimate $=0.05$;

195 standard error: 0.01; FDR =0.02; Fig. 3). The intensity differentially expressed microRNAs

196 (DEmiRs) have modest effects. One microRNA, has-miR-216a-5p, positively associates with 197 average size (estimate $=0.69$; standard error: 0.17; FDR $=0.03$; Fig. 3 ). The estimates represent 198 the $\log _{2}$ fold-change in microRNA abundance for one percent change in intensity or size.

199 Birthweight percentile was not included in the model because of its potential involvement in the 200 causal path of growth trajectory. Of the microRNAs that were associated with growth trajectory 201 with an FDR $<0.1$, four (miR-155, miR-629, let-7c and miR-1246) were also associated with 202 birthweight $($ FDR $<0.1)$ in NHBCS ${ }^{1}$. Because only four participating mothers had pre-eclampsia, 203 it was not included in the primary analysis. However, the potential for pre-eclampsia and other 204 potential confounders (pre-eclampsia, maternal pre-pregnancy BMI, gestational weight gain and 205 birthweight) to attenuate significant associations (Fig. 3) between placental microRNAs and 206 growth trajectory parameters was assessed in sensitivity analyses (Fig. S3). As expected for a 
variable along the causal path, the inclusion of birthweight as a covariate in the model strongly attenuated the estimated $\log _{2}$ fold change for intensity among microRNAs that are also associated with birthweight. Although miR-216a is not associated with birthweight, the addition

210 of birthweight to the model associating transcript abundance to average size attenuated the

211 observed association with size. Interestingly, the addition of categorical gestational weight gain

212 (high, normal, low $)^{42}$ as a covariate in the analysis of miR-216a-5p on average size resulted in a 213 near doubling of the estimated $\log _{2}$ fold change of miR-216a-5p for each $1 \%$ change in average

214 size. The inclusion of maternal pre-pregnancy BMI as a covariate decreased both the effect and

215 the precision of the association of miR-216a-5p with average size.

216 Growth trajectory DEmiR associated mRNAs. Bioinformatic targets of Intensity- and size-

217 associated DEmiRs with an FDR $<0.05$ were collected from the microRNA Data Integration

218 Portal (mirDIP) ${ }^{40}$. In order to enrich our targets with true microRNA-target pairs, we utilized

219 total RNA abundance, assayed from 199 placentae using RNAseq in the RICHS cohort

220 (https://doi.org/10.15139/S3/FUC5EW). mRNA transcripts were considered putative targets of

221 trajectory DEmiRs if they were detectable in RICHS placenta samples. Using these criteria, we

222 found 1,273 putative miR-155 targets, 313 miR-1290 targets, 1,256 let-7c targets, 138 miR-1246

223 targets, 38 miR-629 targets and 747 miR-216a targets. DEmiR mRNA targets were used in

224 pathway analysis.

For each DEmiR, putative target genes were tested for pathway overrepresentation with

226 consensuspathdb (CPDB), against all of the genes that passed QC in the RICHS whole

227 transcriptome RNA-seq analysis ${ }^{41}$. The most significant pathways are listed in Table 3. CPDB

228 integrates pathways from 12 databases, meaning that similar results can be reported across

229 sources. To further prioritize significantly overrepresented pathways, we generated term 
medRxiv preprint doi: https://doi.org/10.1101/2022.02.03.22270310; this version posted February 4, 2022. The copyright holder for this preprint (which was not certified by peer review) is the author/funder, who has granted medRxiv a license to display the preprint in perpetuity.

It is made available under a CC-BY 4.0 International license .

230 frequency matrices for all pathways for which microRNA targets made up more than $20 \%$ of

231 pathway genes and for which the enrichment had an FDR less than 0.02. To assess the

232 microRNA target genes leading the enrichments, a second term frequency matrix was made from

233 the microRNA target genes present in the significant pathways. From these analyses, we found

234 that FGFR1-4 and IGF/R signaling pathways were overrepresented among significant miR-155

235 pathways. The most frequently involved miR-155 target genes were PIK3CA and PIK3R1. For

236 miR-1290, BMP and TGF/beta signaling were the most frequent pathways, with MAPK1 and

237 SMAD2-4 the most frequent target genes. EGF and EGFR pathways were the most frequent

238 among let-7a significant pathways, with MAPK1, PIK3CA and PIK3R1 as the most frequently

239 involved gene targets. There was not repetition among the 13 significant miR-1246 pathways,

240 though the most frequent genes were ADCY1 and PRKACB. Among mir-629 pathways, PTEN

241 was the most frequent pathway, with TNRC6C and AGO1 and AGO4 were the most common

242 gene targets. Finally for the only size DEmiR, miR-216a, regulation of MECP2 was most

243 frequent among pathways, with miR-216a target CALM1-3 as the most frequent genes. When

244 targets of positively-associated growth intensity DEmiRs (Fig. 3) were pooled for pathway

245 analysis, we found that the most frequent pathway terms were FGFR1-4 and the most frequent

246 gene targets were PIK3CA and PIK3R1.

\section{DISCUSSION}

248 In this study, we have described the microRNAs from human placenta that associate with growth

249 trajectory from birth to five years old. We used a shape invariant model with random effects to

250 generate two parameters that describe children's growth intensity and average size during the

251 observation period. We found evidence of microRNAs that vary with both growth parameters

252 (DEmiRs). We narrowed bioinformatically predicted microRNA targets to only those in which 
253 the targeted mRNA was stably expressed in term placenta in the RICHS cohort. These putative

254 DEmiR targets were used in pathway over-representation analysis.

Placental function, which underlies successful pregnancy and may have lasting influence,

256 may be dictated by cellular dynamics - the balance of cell proliferation and differentiation

257 among the terminal placental trophoblast lineages ${ }^{44}$. Recent evidence has suggested that

258 upstream progenitor cells, with the ability to differentiate into cytotrophoblasts,

259 syncytiotrophoblasts and extravillous trophoblasts are present in placenta to term ${ }^{45}$. Diminished

260 abundance of these progenitor cells corresponds to placental dysfunction, like pre-eclampsia ${ }^{45}$.

261 The formation of the placenta relies on the maintenance and proliferation of human

262 trophoblast stem cells, guided, in part by WNT and EGFR signaling ${ }^{46}$. In mice, this maintenance

263 of stemness is reliant on the presence of FGF signaling ${ }^{47}$, however, this may or may not be the

264 case in human placentae ${ }^{46}$. IGF is also important for survival and proliferation of trophoblast

265 stem cells ${ }^{44}$. In our analysis, we see evidence that the EGFR (miR-155, let-7c), FGFR (miR155)

266 and IGFR (let-7c, miR-155, miR-1290) signaling pathways are influenced by growth trajectory

267 microRNAs (Fig. 4).

268 Multipotent villous cytotrophoblasts fuse to form the epithelial, multinucleated

269 syncytiotrophoblast, which facilitates exchange of gases, nutrients and waste for the growing

270 embryo, as well as acting as an endocrine organ to balance the needs of the mother and fetus ${ }^{48}$.

271 Syncytialization is mediated by cAMP and rising intracellular $\mathrm{Ca}+$, as well as continued EGF

272 signaling and Activin $\mathrm{A}^{46,49}$. In this analysis, growth trajectory microRNAs are predicted to

273 target components of the cAMP (miR-1246), calmodulin (miR-216a, miR-1246), EGFR (miR-

274 155, let-7c) pathways, as well as Activin A (miR-1290; Fig. 4). 
276 form the invasive extravillous trophoblast that connects the placenta with the maternal decidua

277 and myometrium to establish maternal blood supply ${ }^{48}$. Signaling through NOTCH1/2 and TGF $\beta$

278 family members (BMP2, Activins) mediate differentiation to the invasive extravillous

279 cytotrophoblast ${ }^{50-52}$. The role of the TFG-beta superfamily in trophoblast differentiation is

280 complicated, as many of the pathway mechanisms overlap ${ }^{53}$, yet TGF-beta1/2/3 53 and NODAL ${ }^{54}$

281 inhibit the invasive phenotype and favor syncytialization while BMP2 and Activin A/B/AB all

282 favor the invasive phenotype ${ }^{50,51}$. In this analysis, we found evidence that growth trajectory

283 associated microRNAs target components of the NOTCH1/2 (miR-629) and TGF $\beta$ superfamily

284 (miR-1290) signaling cascades (Fig. 4).

Although these processes described above were primarily described in first trimester

286 placentae and cell culture, the placental cytotrophoblasts continue to maintain the

287 syncytiotrophoblast and extravillous trophoblasts to term ${ }^{45}$. The discovery of trophoblast

288 progenitor cells in term placenta suggests that some of the signaling pathways relevant in early

289 gestation, remain important later in gestation. Within this assumption, our findings suggest that

290 microRNAs influence the cellular dynamics of placenta at term, which in turn regulate the

291 plasticity and efficiency of the placenta to support fetal growth. This initial growth primes the

292 neonate's metabolism for early growth patterns. However, it is also likely that some of the

293 growth factors under microRNA influence have specific functions at term that are in addition to

294 or exclusive of their functions in early gestation. For instance, while EGF signaling guides

295 trophoblast maintenance, proliferation and differentiation in early gestation, it may stimulate the

296 release of hormones to the maternal and fetal circulations at term ${ }^{44}$. 
Some of the growth trajectory-associated microRNAs described in this analysis have been previously associated with birthweight in the $\mathrm{NHBCS}^{1}$ including miR-155-5p, mir-629-3p, let-7c and miR-1246. Birthweight was not included in our models, because it is an upstream measure of weight, and included as the initial weight in the growth trajectory analysis.

301 Interestingly, the association of miR-1290 with growth trajectory is not sensitive to the inclusion

302 of birthweight to the model, suggesting that placental miR-1290 relates to early childhood 303 growth independently of birthweight.

Growth trajectory-associated microRNAs have also been associated with placental

305 characteristics in other studies. In cultured extravillous trophoblasts, miR-155 inhibits cell

306 proliferation by down-regulating cyclin D1/p27 ${ }^{55}$. In cultured cytotrophoblasts, Let-7c is

307 associated with reduced proliferation potential and syncytialization ${ }^{56,57}$. Let-7c is associated with

308 the $\mathrm{WNT} / \beta$-catenin signaling pathway in other progenitor cell types ${ }^{58}$. In cultured extravillous

309 trophoblasts, miR-1290 promotes rearrangement of maternal endometrium via placental

310 exosomes ${ }^{59}$. miR-1246 has been associated with syncytialization and targeting inhibitors of the

$311 \mathrm{WNT} / \beta$-catenin signaling pathway ${ }^{60}$.

To our knowledge, this is the first study to examine the relationships between human

313 placental microRNAs and early childhood growth trajectory. Our results suggest that placental

314 microRNAs effect signaling cascades central to trophoblast proliferation, differentiation and

315 function. Most importantly, our results underscore the importance of placental function and the 316 intrauterine environment in establishing early growth trends.

317 Our findings should be interpreted within the context of this study's limitations. This is

318 an observational study in which RNA was assayed from term placentae. Thus, we cannot

319 conclude that our results are representative of microRNA associations throughout development. 
medRxiv preprint doi: https://doi.org/10.1101/2022.02.03.22270310; this version posted February 4, 2022. The copyright holder for this preprint (which was not certified by peer review) is the author/funder, who has granted medRxiv a license to display the preprint in perpetuity.

It is made available under a CC-BY 4.0 International license .

320 We used DESeq2 to identify associations between miRNA expression and childhood growth,

321 where childhood growth was determined using child-specific estimates of size and intensity

322 derived using SITAR. In DESeq2, microRNA abundances (dependent variable) are regressed on

323 size or intensity (independent variable), allowing us to examine the association of early

324 childhood growth on placental microRNA expression. Although the models employed in

325 DESeq2 are temporally reversed in terms of what is being modeled as dependent and

326 independent variables, DESeq2 represents the best choice for modeling gene expression data as it

327 accounts for the over-dispersion of RNA-sequencing count data. While the estimates generated

328 by these models may be less intuitive and temporally reversed from our hypothesis, the

329 associations between placental microRNA expression with growth trajectory patterns ascertained

330 using such models are nevertheless valid. We adjusted for likely confounders in our study, but

331 cannot rule out the possibility that unmeasured or residual confounding remains in our analysis.

332 Potential confounders are maternal BMI, gestational weight gain and pre-eclampsia. Sensitivity

333 analysis suggests that the addition of these variables to our models would have little to no effect

334 on our conclusions, though some of our top findings are sensitive to one or both. To limit

335 unknown statistical confounding (e.g. differing cellular composition between individuals or

336 population stratification), our models are adjusted using surrogate variable analysis. This is a

337 data-driven approach that may incorrectly estimate confounding elements, adding variability to

338 our model. Recent research indicates that SVA is one of the more robust and reliable methods in

339 studies such as ours ${ }^{61}$. Lastly, the cohort utilized in this study consisted predominantly of

340 healthy white mothers from a rural New England region of the United States, potentially limiting

341 the generalizability of our findings. 


\section{AUTHOR CONTRIBUTIONS:}

344 EMK, DCK, KH, JC, DG-D, MRK and CJM conceptualized and designed the study. KH, AB

345 and DP acquired data. EMK analyzed and interpreted the data. EMK Drafted the article. KH,

346 AB, DP, DCK, KH, JC, DG-D, UR, MRK and CJM critically reviewed and carefully revised the

347 article. All authors approved of the version to be published.

\section{FINANCIAL SUPPORT:}

349 This work was supported by the National Institutes of Health (NIEHS R24ES028507,

350 R01ES025145, P30ES019776, NIMHD R01MD011698 and NICHD 1K99HD104991-01).

\section{DISCLOSURE STATEMENT:}

352 The authors declare they have no competing interests or personal relationships that would 353 potentially influence the work presented in this paper.

\section{ETHICAL STANDARDS:}

355 All participants provided written, informed consent and all protocols were approved by the IRBs

356 at the Women \& Infants Hospital of Rhode Island, Dartmouth College and Emory University, 357 respectively. 


\section{REFERENCES}

360 1. Kennedy, E. M. et al. Placental microRNA expression associates with birthweight through

361 control of adipokines: results from two independent cohorts. Epigenetics 1-13 (2020)

362 doi:10.1080/15592294.2020.1827704.

363 2. Guo, D. et al. Elevated microRNA-141-3p in placenta of non-diabetic macrosomia regulate 364 trophoblast proliferation. EBioMedicine 38, 154-161 (2018).

365

3. Timofeeva, A. V. et al. Identification of potential early biomarkers of preeclampsia. Placenta 61, 61-71 (2018).

4. Wu, L. et al. miR-181a-5p suppresses invasion and migration of HTR-8/SVneo cells by directly targeting IGF2BP2. Cell Death Dis. 9, 1-14 (2018).

5. Enquobahrie, D. A. et al. Placental microRNA expression in pregnancies complicated by preeclampsia. Am. J. Obstet. Gynecol. 204, 178.e12-178.e21 (2011).

371 6. Vashukova, E. S. et al. Placental microRNA expression in pregnancies complicated by superimposed pre-eclampsia on chronic hypertension. Mol. Med. Rep. 14, 22-32 (2016).

7. Yang, S., Li, H., Ge, Q., Guo, L. \& Chen, F. Deregulated microRNA species in the plasma and placenta of patients with preeclampsia. Mol. Med. Rep. 12, 527-534 (2015).

8. Niu, Z. et al. MicroRNA-30a-3p is overexpressed in the placentas of patients with preeclampsia and affects trophoblast invasion and apoptosis by its effects on IGF-1. Am. J. Obstet. Gynecol. 218, 249.e1-249.e12 (2018). pathogenesis of severe preeclampsia through downregulation of endothelial nitric oxide synthase. Mol. Med. Rep. 12, 5383-5390 (2015). 
medRxiv preprint doi: https://doi.org/10.1101/2022.02.03.22270310; this version posted February 4, 2022. The copyright holder for this preprint (which was not certified by peer review) is the author/funder, who has granted medRxiv a license to display the preprint in perpetuity.

It is made available under a CC-BY 4.0 International license .

10. Zhu, X., Han, T., Sargent, I. L., Yin, G. \& Yao, Y. Differential expression profile of microRNAs in human placentas from preeclamptic pregnancies vs normal pregnancies. Am. J. Obstet. Gynecol. 200, 661.e1-661.e7 (2009).

384 11. Carreras-Badosa, G. et al. Dysregulation of Placental miRNA in Maternal Obesity Is Associated With Pre- and Postnatal Growth. J. Clin. Endocrinol. Metab. 102, 2584-2594 (2017).

12. Li, J. et al. A MicroRNA Signature in Gestational Diabetes Mellitus Associated with Risk of Macrosomia. Cell. Physiol. Biochem. 37, 243-252 (2015).

13. Awamleh, Z., Gloor, G. B. \& Han, V. K. M. Placental microRNAs in pregnancies with early onset intrauterine growth restriction and preeclampsia: potential impact on gene expression and pathophysiology. BMC Med. Genomics 12, 91 (2019).

14. Higashijima, A. et al. Characterization of placenta-specific microRNAs in fetal growth

394 15. Rahman, M. L. et al. Regulation of birthweight by placenta-derived miRNAs: evidence from an arsenic-exposed birth cohort in Bangladesh. Epigenetics 13, 573-590 (2018).

16. Wang, D., Na, Q., Song, W.-W. \& Song, G.-Y. Altered Expression of miR-518b and miR519a in the Placenta is Associated with Low Fetal Birth Weight. Am. J. Perinatol. 31, 729734 (2014).

17. Meng, M. et al. Whole genome miRNA profiling revealed miR-199a as potential placental pathogenesis of selective fetal growth restriction in monochorionic twin pregnancies.

Placenta 92, 44-53 (2020). 
18. Thamotharan, S. et al. Differential microRNA expression in human placentas of term intrauterine growth restriction that regulates target genes mediating angiogenesis and amino acid transport. PLoS ONE 12, (2017).

19. Huang, L. et al. Increased levels of microRNA-424 are associated with the pathogenesis of fetal growth restriction. Placenta 34, 624-627 (2013).

20. Östling, H., Kruse, R., Helenius, G. \& Lodefalk, M. Placental expression of microRNAs in infants born small for gestational age. Placenta 81, 46-53 (2019).

21. Guo, L. et al. Differentially expressed microRNAs and affected biological pathways revealed by modulated modularity clustering (MMC) analysis of human preeclamptic and IUGR placentas. Placenta 34, 599-605 (2013).

22. Barker, D. J. P. \& Thornburg, K. L. Placental programming of chronic diseases, cancer and lifespan: a review. Placenta 34, 841-845 (2013).

414 23. Red-Horse, K. et al. Trophoblast differentiation during embryo implantation and formation of the maternal-fetal interface. J. Clin. Invest. 114, 744-754 (2004).

24. Kaufmann, P., Mayhew, T. M. \& Charnock-Jones, D. S. Aspects of Human Fetoplacental Vasculogenesis and Angiogenesis. II. Changes During Normal Pregnancy. Placenta 25, 114-

419 25. Bartel, D. P. Metazoan MicroRNAs. Cell 173, 20-51 (2018).

420 26. Quévillon Huberdeau, M. \& Simard, M. J. A guide to microRNA-mediated gene silencing. $421 \quad$ FEBS J. 286, 642-652 (2019). reciprocal relationship. Nat. Rev. Genet. 13, 271-282 (2012). 
28. Hayder, H., O’Brien, J., Nadeem, U. \& Peng, C. MicroRNAs: crucial regulators of placental development. Reproduction 155, R259-R271 (2018).

29. Peng, S. et al. Genetic regulation of the placental transcriptome underlies birth weight and risk of childhood obesity. PLoS Genet. 14, (2018).

30. Martin, M. Cutadapt removes adapter sequences from high-throughput sequencing reads.

$$
\text { EMBnet.journal 17, 10-12 (2011). }
$$

31. Ewels, P., Magnusson, M., Lundin, S. \& Käller, M. MultiQC: summarize analysis results for

32. Friedländer, M. R., Mackowiak, S. D., Li, N., Chen, W. \& Rajewsky, N. miRDeep2 accurately identifies known and hundreds of novel microRNA genes in seven animal clades.

34. Griffiths-Jones, S., Saini, H. K., van Dongen, S. \& Enright, A. J. miRBase: tools for Biol. 11, R106 (2010).

36. Cole, T. J., Donaldson, M. D. C. \& Ben-Shlomo, Y. SITAR—a useful instrument for growth curve analysis. Int. J. Epidemiol. 39, 1558-1566 (2010).

443 37. Leek, J. T., Johnson, W. E., Parker, H. S., Jaffe, A. E. \& Storey, J. D. The sva package for removing batch effects and other unwanted variation in high-throughput experiments. 
medRxiv preprint doi: https://doi.org/10.1101/2022.02.03.22270310; this version posted February 4, 2022. The copyright holder for this preprint (which was not certified by peer review) is the author/funder, who has granted medRxiv a license to display the preprint in perpetuity.

It is made available under a CC-BY 4.0 International license .

446 38. Leek, J. T. svaseq: removing batch effects and other unwanted noise from sequencing data.

$447 \quad$ Nucleic Acids Res. 42, e161 (2014).

448 39. Love, M. I., Huber, W. \& Anders, S. Moderated estimation of fold change and dispersion for

449 RNA-seq data with DESeq2. Genome Biol. 15, (2014).

450 40. Tokar, T. et al. mirDIP 4.1-integrative database of human microRNA target predictions.

$451 \quad$ Nucleic Acids Res. 46, D360-D370 (2018).

452 41. Kamburov, A. et al. ConsensusPathDB: toward a more complete picture of cell biology.

$453 \quad$ Nucleic Acids Res. 39, D712-717 (2011).

454 42. Institute of Medicine (US) and National Research Council (US) Committee to Reexamine IOM Pregnancy Weight Guidelines. Weight Gain During Pregnancy: Reexamining the

457 43. Fenton, T. R. \& Kim, J. H. A systematic review and meta-analysis to revise the Fenton 458 growth chart for preterm infants. BMC Pediatr. 13, 59 (2013).

459 44. Aplin, J. D. \& Jones, C. J. P. Cell dynamics in human villous trophoblast. Hum. Reprod.

$460 \quad$ Update 27, 904-922 (2021).

461 45. Gamage, T. K. et al. Side-Population Trophoblasts Exhibit the Differentiation Potential of a

462 Trophoblast Stem Cell Population, Persist to Term, and are Reduced in Fetal Growth

463 Restriction. Stem Cell Rev. Rep. 16, 764-775 (2020).

464 46. Okae, H. et al. Derivation of Human Trophoblast Stem Cells. Cell Stem Cell 22, 50-63.e6

$465 \quad$ (2018).

466 47. Latos, P. A. \& Hemberger, M. From the stem of the placental tree: trophoblast stem cells and

467 their progeny. Development 143, 3650-3660 (2016). 
48. Knöfler, M. et al. Human placenta and trophoblast development: key molecular mechanisms and model systems. Cell. Mol. Life Sci. 76, 3479-3496 (2019).

49. Gupta, S. K., Malhotra, S. S., Malik, A., Verma, S. \& Chaudhary, P. Cell Signaling Pathways Involved During Invasion and Syncytialization of Trophoblast Cells. Am. J. Reprod. Immunol. 75, 361-371 (2016).

50. Zhao, H.-J. et al. Bone morphogenetic protein 2 promotes human trophoblast cell invasion by upregulating N-cadherin via non-canonical SMAD2/3 signaling. Cell Death Dis. 9, 1-12

51. Zhao, H.-J. et al. Bone Morphogenetic Protein 2 Promotes Human Trophoblast Cell Invasion by Inducing Activin A Production. Endocrinology 159, 2815-2825 (2018).

52. Haider, S. et al. Notch1 controls development of the extravillous trophoblast lineage in the human placenta. Proc. Natl. Acad. Sci. U. S. A. 113, E7710-E7719 (2016).

53. Li, Y., Yan, J., Chang, H.-M., Chen, Z.-J. \& Leung, P. C. K. Roles of TGF- $\beta$ Superfamily Proteins in Extravillous Trophoblast Invasion. Trends Endocrinol. Metab. 32, 170-189 (2021).

54. Nadeem, L. et al. Nodal Signals through Activin Receptor-Like Kinase 7 to Inhibit Trophoblast Migration and Invasion: Implication in the Pathogenesis of Preeclampsia. Am. J.

55. Dai, Y. et al. MicroRNA-155 inhibits proliferation and migration of human extravillous trophoblast derived HTR-8/SVneo cells via down-regulating cyclin D1. Placenta 33, 824- 
491 57. McWhorter, E. S. et al. LIN28B regulates androgen receptor in human trophoblast cells

492 through Let-7c. Mol. Reprod. Dev. 86, 1086-1093 (2019).

493 58. Modi, B. P. et al. Expression patterns of the chromosome 21 MicroRNA cluster (miR-99a,

494 miR-125b and let-7c) in chorioamniotic membranes. Placenta 49, 1-9 (2017).

495 59. Shi, S. et al. Placental trophoblast cell-derived exosomal microRNA-1290 promotes the

496 interaction between endometrium and embryo by targeting LHX6. Mol. Ther. - Nucleic

497 Acids 26, 760-772 (2021).

498 60. Muralimanoharan, S., Kwak, Y.-T. \& Mendelson, C. R. Redox-Sensitive Transcription

499 Factor NRF2 Enhances Trophoblast Differentiation via Induction of miR-1246 and Aromatase. Endocrinology 159, 2022-2033 (2018).

501 61. van Rooij, J. et al. Evaluation of commonly used analysis strategies for epigenome- and 502 transcriptome-wide association studies through replication of large-scale population studies.

$503 \quad$ Genome Biol. 20, 235 (2019). 


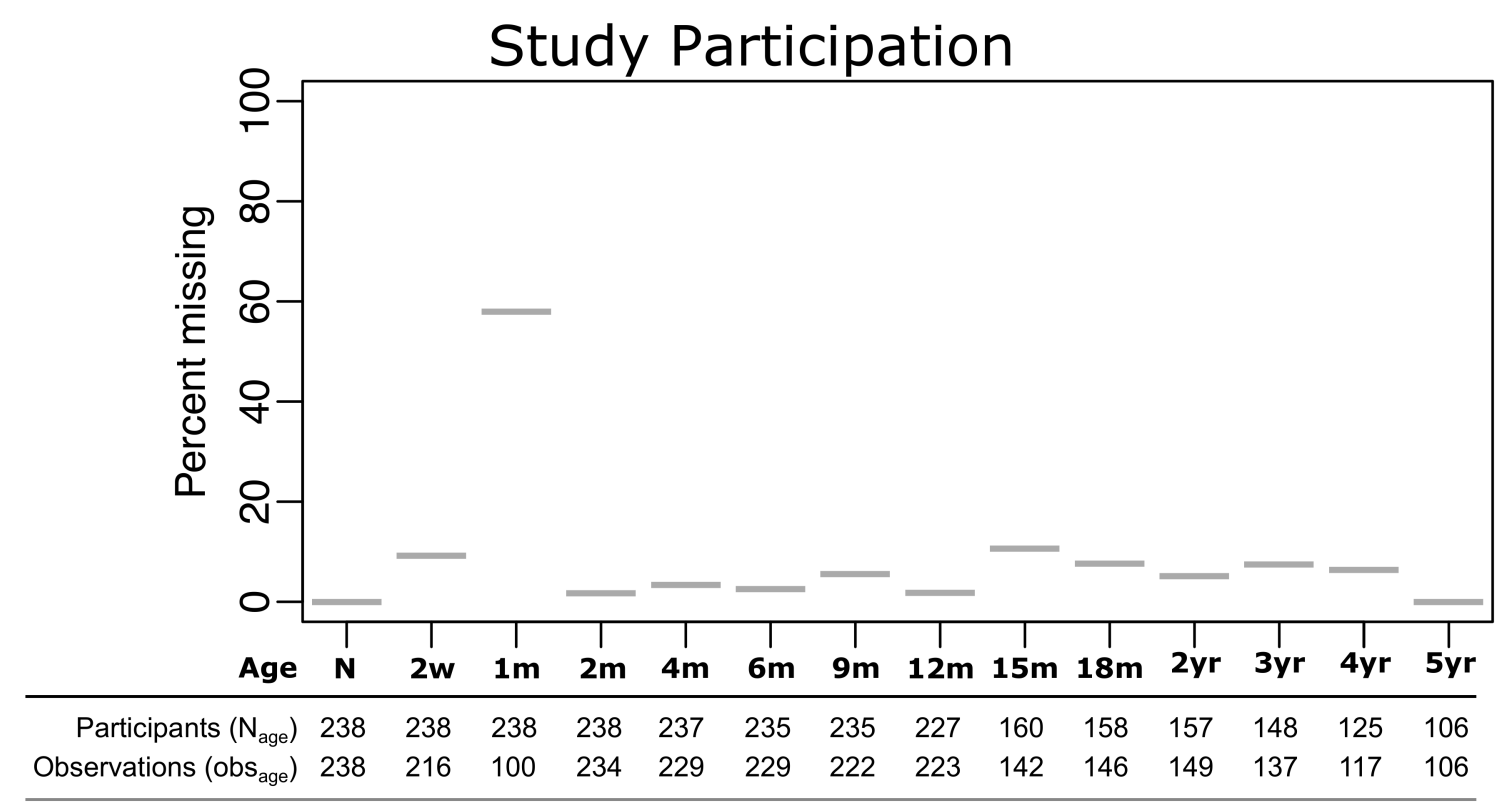

Fig. 1. Participation in weight observation collection. Weights were collected at up to 14

509 separate time points for each child (x-axis). With the exception of the 1-month $(1 \mathrm{~m})$ measure,

510 missingness rate (y-axis) was low, meaning that observations at each measurement (obsage)

511 remained high despite missing data after 12 months $\left(12 \mathrm{~m}, \mathrm{~N}_{\text {age }}\right)$. 


\section{NHBCS Growth Curves}

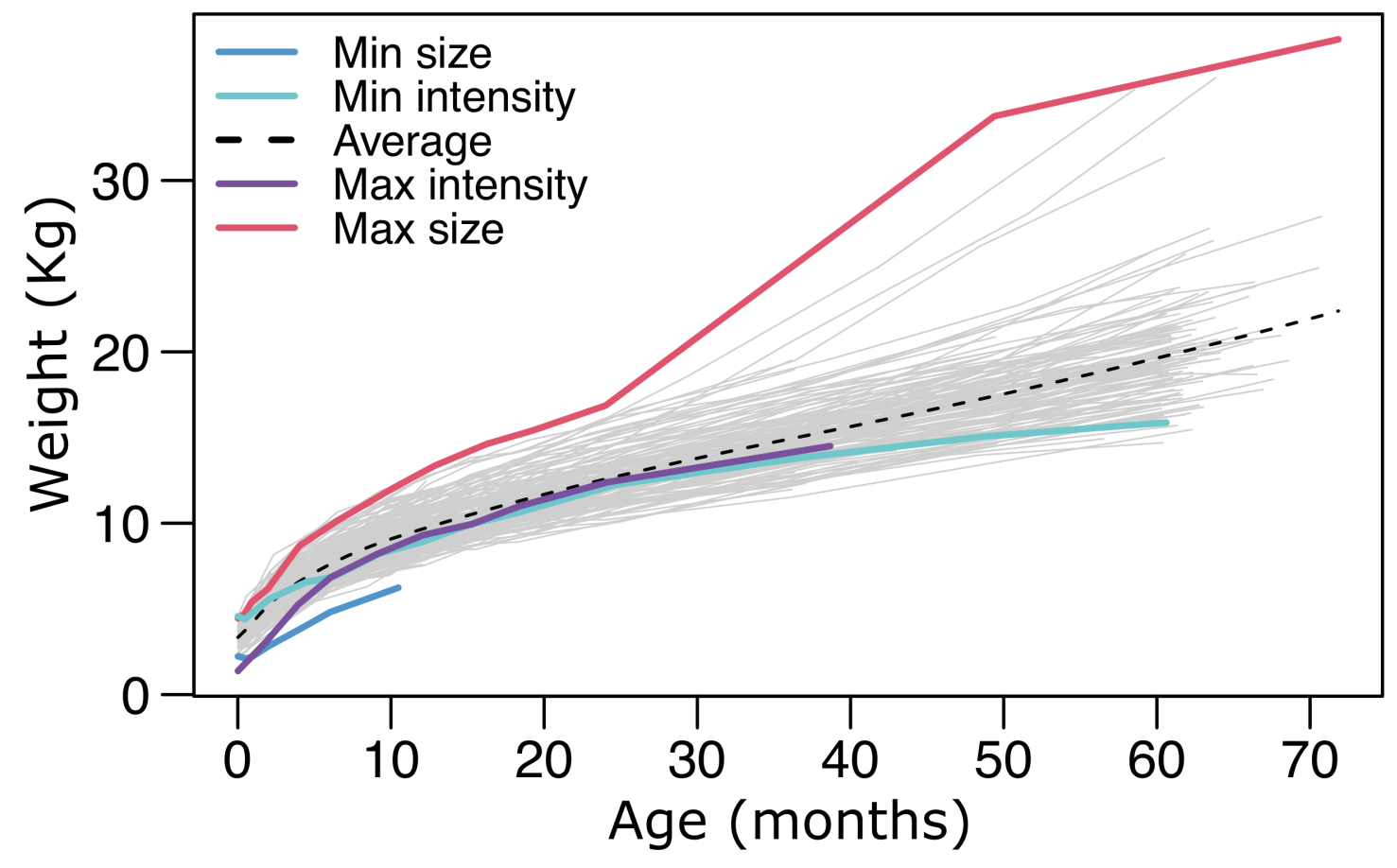

514 Fig. 2. NHBCS Growth Curves. Unadjusted growth curves are plotted for all participants in

515 this analysis $(\mathrm{N}=238)$. The mean growth curve, calculated by SITAR, is plotted as a dashed

516 line. The growth curves representing the minimum and maximum average size are plotted in blue

517 and red, respectively. Deviations in average size appear as vertical shifts from the mean curve.

518 The growth curves representing the minimum and maximum growth intensities are plotted in

519 cyan and purple, respectively. Deviations in growth intensity appear as rotations

520 (counter/clockwise) of the mean curve. 


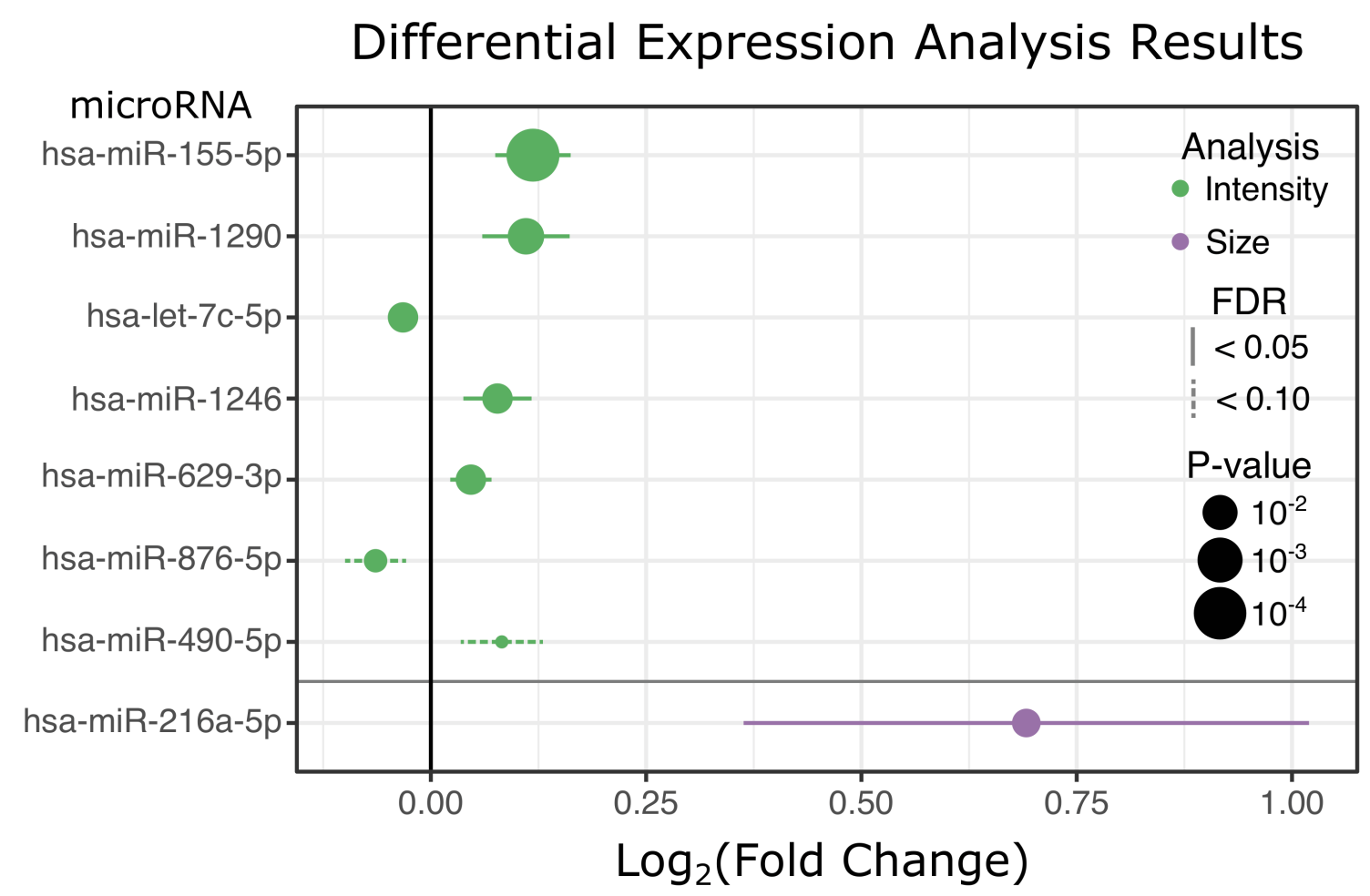

522 Fig. 3. Differential expression analysis results. microRNAs with FDR $<0.1$ in either analysis

523 are listed on the y-axis. Their $\log _{2}$ fold change for a one percent change in either growth intensity

524 (green) or average size (purple) is on the x-axis. 95\% confidence intervals are illustrated with

525 either solid (estimate has FDR $<0.05$ ) or dashed (estimate has FDR $<0.1$ ) lines. Point size is

526 proportional to $-\log 10(\mathrm{P}$-value), such that larger points represent smaller p-values. 


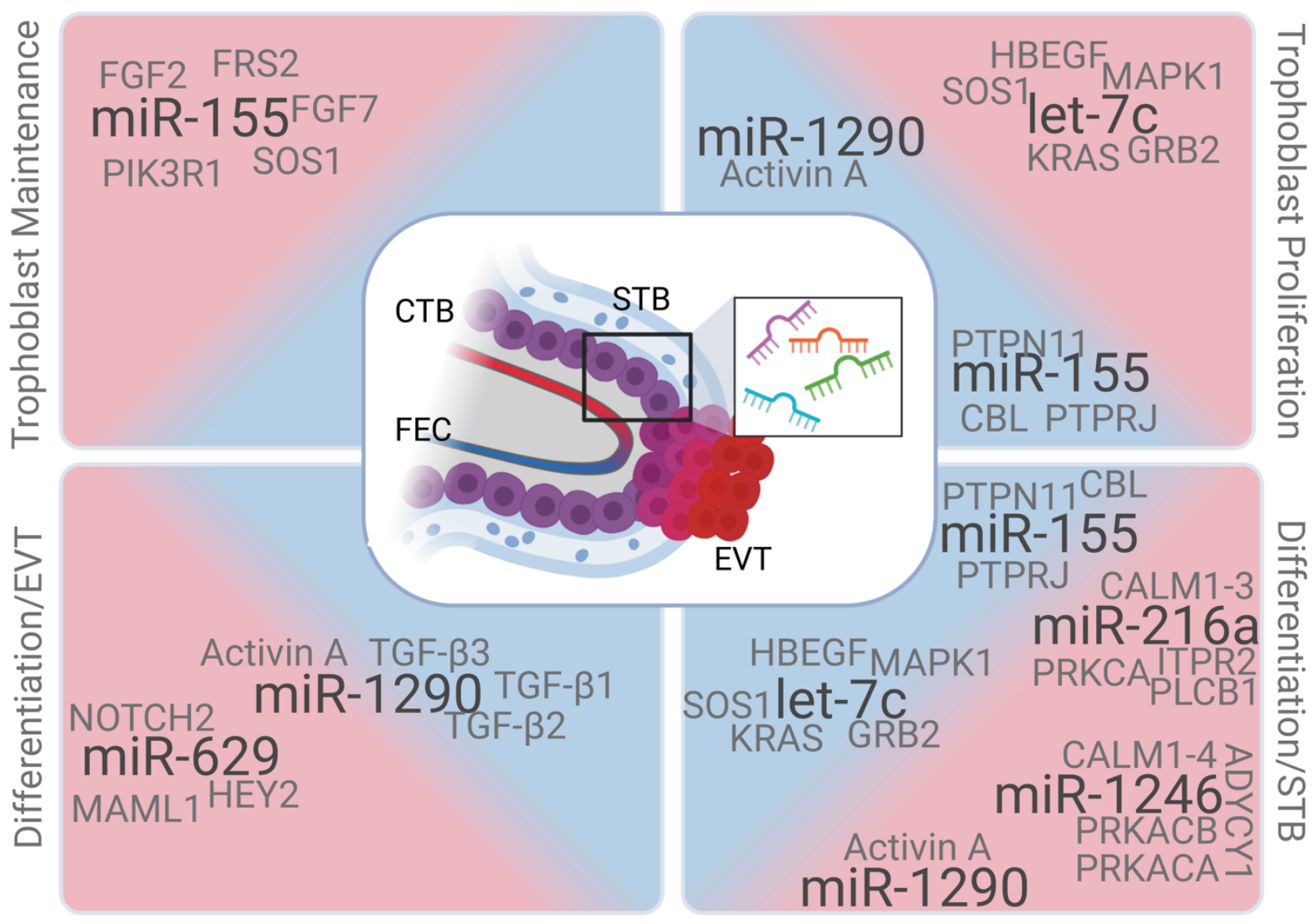

Fig. 4. The potential roles of growth trajectory microRNAs in the cellular dynamics of

placental trophoblasts. A terminal placental villous is illustrated in the center of the Fig.,

531 representing the involved placental cell types from which microRNAs in our study could arise:

532 fetal endothelial cells (FEC), cytotrophoblasts (CTB), syncytiotrophoblasts (STB) and

533 extravillous trophoblasts (EVT). Growth trajectory microRNAs are listed (in black) along with

534 their influential targets (gray) in the processes we predict they may influence (trophoblast stem

535 maintenance, proliferation and differentiation to the syncytiotrophoblast (STB) or extravillous

536 trophoblast (EVT) terminal lineage). microRNAs and their putative targets in the central blue or

537 outer red areas are predicted to encourage or inhibit the given process, respectively. Created with

538 BioRender.com. 
TABLES

Table 1. Cohort demographics

\begin{tabular}{|c|c|c|}
\hline & Intensity $^{\mathrm{a}}(\mathrm{n}=\mathbf{2 3 5})$ & $\operatorname{Size}^{a}(n=230)$ \\
\hline \multicolumn{3}{|l|}{ MATERNAL CHARACTERISTICS } \\
\hline Age - mean (range) & $31(18-45)$ & $31(18-45)$ \\
\hline Education (>high school) - \% (n) & $91(206)$ & $90(208)$ \\
\hline Parity - mean (range) & $1(0-4)$ & $1(0-4)$ \\
\hline Existing Diabetes & $0.4 \%(1)$ & $0.4 \%(1)$ \\
\hline Gestational Diabetes & $5 \%(11)$ & $5 \%(12)$ \\
\hline Pregnancy hypertension & $3 \%(7)$ & $3 \%(7)$ \\
\hline Pre-eclampsia & $2 \%(4)$ & $2 \%(4)$ \\
\hline Pre-pregnancy BMI - mean (range) & $26(17-46)$ & $26(17-46)$ \\
\hline \multicolumn{3}{|l|}{ Gestational weight gain category $^{b}$} \\
\hline Low $^{c}-\%(n)$ & $7 \%(16)$ & $6.6 \%(15)$ \\
\hline Normal $^{\mathrm{d}}-\%(n)$ & $26 \%(59)$ & $25.7 \%(58)$ \\
\hline $\operatorname{High}^{\mathrm{e}}-\%(n)$ & $67 \%(155)$ & $67.7 \%(153)$ \\
\hline \multicolumn{3}{|l|}{ INFANT CHARACTERISTICS } \\
\hline Race (white) - \% (n) & $100 \%(235)$ & $100 \%(235)$ \\
\hline Gestational age (wks) - mean (range) & $40(31-42)$ & $39(31-42)$ \\
\hline Birthweight (g) - mean (range) & $3464(1380-4572)$ & $3468(1380-4572)$ \\
\hline \multicolumn{3}{|l|}{ Birthweight group } \\
\hline $\mathrm{SGA}^{\mathrm{f}}-\%(n)$ & $4 \%(9)$ & $3 \%(8)$ \\
\hline $\mathrm{AGA}^{\mathrm{g}}-\%(n)$ & $86 \%(206)$ & $88 \%(202)$ \\
\hline $\mathrm{LGA}^{\mathrm{h}}-\%(n)$ & $10 \%(20)$ & $9 \%(20)$ \\
\hline Sex (Female) - \% (n) & $49 \%(116)$ & $49 \%(112)$ \\
\hline
\end{tabular}

${ }^{\mathrm{a} C}$ Cohort characteristics and sample size for the SITAR Intensity and Size parameter analyses, respectively

${ }^{b}$ NHBCS statistics for gestational weight gain were based on the 230 samples with available measures in the Intensity parameter analysis and 226 for the size analysis. ${ }^{\text {e} H i g h ~-~ G e s t a t i o n a l ~ w e i g h t ~ g a i n ~ a b o v e ~ r e c o m m e n d a t i o n ~ f o r ~ p r e-p r e g n a n c y ~ B M I ~ c a t e g o r y ~}{ }^{42}$ ${ }^{\text {fSGA }}$ - Infants born with a birthweight percentile $\leq 10^{43}$

549 gAGA - Infants born with a birthweight between the $10^{\text {th }}$ and $90^{\text {th }}$ percentiles ${ }^{43}$

550 hGA - Infants born with a birthweight percentile $\geq 90^{43}$ 
medRxiv preprint doi: https://doi.org/10.1101/2022.02.03.22270310; this version posted February 4, 2022. The copyright holder for this preprint (which was not certified by peer review) is the author/funder, who has granted medRxiv a license to display the preprint in perpetuity.

It is made available under a CC-BY 4.0 International license.

\section{Table 2. Growth trajectory correlates}

\begin{tabular}{llccc}
\hline Variable & Analysis & Estimate & Error & P-value \\
\hline Pre-eclampsia & Intensity & 3.78 & 1.76 & 0.03 \\
Parity & Intensity & -0.64 & 0.22 & $4 \times 10^{-3}$ \\
Gestational weight gain category (low v normal) & Intensity & 2.10 & 0.99 & 0.03 \\
Gestational age & Intensity & -1.07 & 0.14 & $3 \times 10^{-13}$ \\
Birthweight percentile & Intensity & -0.06 & 0.01 & $1 \times 10^{-11}$ \\
\hline Maternal education & Size & -0.45 & 0.22 & 0.04 \\
Primigravida & Size & 0.32 & 0.15 & 0.03 \\
Gestational weight gain category (high v normal) & Size & 0.4 & 0.15 & $9 \times 10^{-3}$ \\
Birthweight percentile & Size & 0.01 & $2 \times 10^{-3}$ & $7 \times 10^{-8}$ \\
\hline
\end{tabular}


medRxiv preprint doi: https://doi.org/10.1101/2022.02.03.22270310; this version posted February 4, 2022. The copyright holder for this preprint (which was not certified by peer review) is the author/funder, who has granted medRxiv a license to display the preprint in perpetuity.

It is made available under a CC-BY 4.0 International license.

Table 3. Top significant pathway for growth trajectory DEmiRs

\begin{tabular}{|c|c|c|c|c|}
\hline microRNA & Analysis & Pathway & q-value & $\begin{array}{c}\% \text { pathway } \\
\text { genes as targets }\end{array}$ \\
\hline hsa-miR-155-5p & Intensity & FLT3 Signaling & $4 \times 10-3$ & 42 \\
\hline hsa-miR-1290 & Intensity & $\begin{array}{l}\text { Regulation of cytoplasmic and } \\
\text { nuclear SMAD } 2 / 3 \text { signaling }\end{array}$ & $2 \times 10^{-4}$ & 24 \\
\hline hsa-let-7c-5p & Intensity & $\begin{array}{l}\text { EGF-EGFR Signaling } \\
\text { Pathway }\end{array}$ & $2 \times 10^{-5}$ & 47 \\
\hline hsa-miR-1246 & Intensity & L1CAM interactions & $7 \times 10^{-3}$ & 24 \\
\hline hsa-629-3p & Intensity & Signaling by NOTCH & $6 \times 10^{-3}$ & 21 \\
\hline $\begin{array}{l}\text { hsa-miR-216a- } \\
5 \mathrm{p}\end{array}$ & Size & EGFR1 & $3 \times 10^{-3}$ & 11 \\
\hline
\end{tabular}

